A
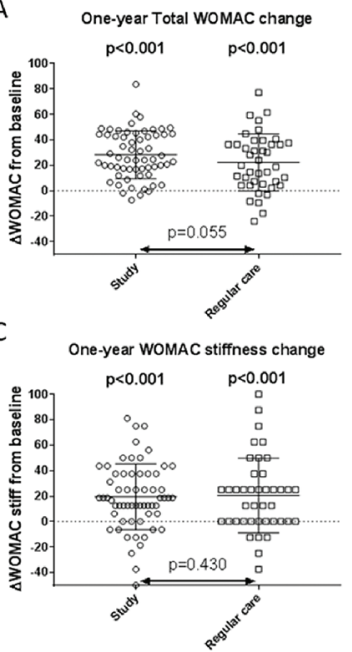

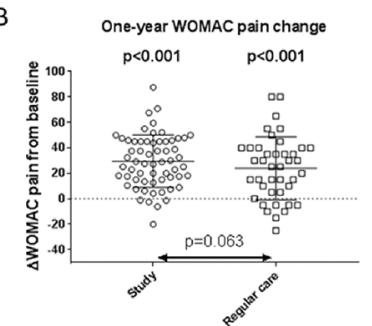

D

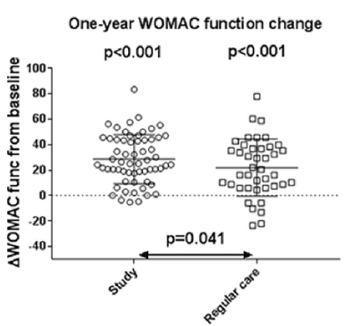

Figure 1: One-year change in total WOMAC score (A) and the WOMAC subscales pain (B), stiffness (C) and function (D) for patients treated with knee joint distraction in clinical studies and in regular care. In all graphs, the p-values above patient groups indicate significant one-year changes while the $\mathrm{p}$-values between patient groups indicate the differences between the groups, corrected for baseline values.

Abstract THU0434 - Figure 1

Conclusion: KJD results in a statistically and clinically significant 1-year improvement in total WOMAC and subscales for most patients. There were no clinically relevant differences between study and regular care patients. Longer follow-up will show whether this is maintained. As such, KJD not only shows good efficacy in study conditions, but also in regular care and can be a joint-preserving treatment of choice for young knee OA patients.

\title{
REFERENCES:
}

[1] Van der Woude et al, Cartilage 2017;8(3):263-271.

[2] Jansen et al, Cartilage (accepted)

Disclosure of Interests: Mylène Jansen: None declared, Simon Mastbergen Grant/research support from: FOREUM; Dutch Arthritis Society, Michelle Van Empelen: None declared, Esmee Kester: None declared, Floris Lafeber Shareholder of: ArthroSave, Grant/research support from: FOREUM; Dutch Arthritis Society, Roel Custers: None declared DOI: 10.1136/annrheumdis-2019-eular.2786

\section{THU0435 ASSESING THE EFFECTS OF PULSED ULTRASOUND TREATMENT ON PAIN, FUNCTIONALITY, SYNOVIAL FLUID AND CARTILAGE THICKNESS, IN KNEE OSTEOARTHRITIS}

Ali Karakas ${ }^{1}$, Muhammed Abdulkerim Şahin ${ }^{2}$, Hülya Ellidokuz ${ }^{3}$, Banu Dilek ${ }^{2}$, Özlem Şenocak ${ }^{2}{ }^{1}$ Dokuz Eylül Üniversitesi Hastanesi, Department of Physical Medicine and Rehabilitation, Department of Rheumatology, izmir, Turkey, ${ }^{2}$ Dokuz Eylül Üniversitesi Hastanesi, Department of Physical Medicine and Rehabilitation, izmir, Turkey, ${ }^{3}$ Dokuz Eylül Üniversitesi Hastanesi, Institute of Oncology, Department of Preventive Oncology, izmir, Turkey

Background: Osteoarthritis $(\mathrm{OA})$ is a progressive rheumatic disease which is the most common cause of musculoskeletal pain and functional impairment, particularly in the elderly group. Ultrasound therapy is one of the most commonly used physical modalities in the $\mathrm{OA}$ treatment. It has deep heating effect and increases tissue regeneration, blood flow and metabolic effects while reducing the inflammation. In addition, it increases the cartilage regeneration according to certain in vivo and in vitro studies (1).

Objectives: To research the effect of pulsed ultrasound treatment on pain, functionality, synovial fluid and cartilage thickness in knee osteoarthritis.

Methods: This study was a randomised-controlled and parallel group study. 96 patients (79 females and 17 males) were included to study who had knee pain, aged between 45-75 years. They also have diagnosed as knee osteoarthritis according to ACR diagnostic criteria and their Kellgren-Lawrence grades were $\leq 3$. These patients were divided in two groups randomly: Treatment group (exercise + US), (9 male, 39

female), control group (exercise + Sham US), (8 male, 40 female). The patients in the treatment group were treated with a $1 \mathrm{MHz}$ probe and a density of $1 \mathrm{w} / \mathrm{cm}^{2}, 1: 4$ for 10 minutes, and 3 sessions a week for 8 weeks. Sham US treatment was applied to each group at the same time. Both groups received a home exercise program including knee range of motion and isometric strengthening exercises. All patients were evaluated by ultrasonographic measurements and quality of life tests VAS (Visuel Analog Scale) rest, VAS walking, Timed Up and Go Test, WOMAC Questionnaire scores (before treatment, after treatment, 3 months after treatment).

Results: 9 out of 48 patients in the treatment group and 12 out of 48 patients in the control group were excluded from the study because they did not continue treatment or come to the control. The distribution of groups was similar (Table-1). VAS rest, VAS walking, Timed up and go test, WOMAC questionnaire scores, were improved statistically significant in both groups $(\mathrm{P}<0.05)$, but group effect could not be demonstrated $(P>0.05)$ There were no statistically significant results in terms of both synovial fluid and femoral cartilage thickness measurements $(P>0.05)$ (Table 2).

Abstract THU0435 -Table 1.

\begin{tabular}{|c|c|c|c|}
\hline Table-1 & $\begin{array}{c}\text { Treatment group } \\
\text { (exercise + US) } \\
n=48\end{array}$ & $\begin{array}{c}\text { Control group } \\
\text { (exercise + Sham US) } \\
n=48\end{array}$ & $\mathbf{P}$ \\
\hline Ase & $58.52=7.28$ & $60.02=7.43$ & 0,320 \\
\hline Gender & 39 female 9 male & 40 temale 8 male & 0.789 \\
\hline $\operatorname{BMII}\left(\mathbf{k g} / \mathbf{m}^{2}\right)$ & $28.59 \times 4.97$ & $29.29 \times 9.23$ & 0,700 \\
\hline VASRest & $4.75=2.23$ & $4.37=1.90$ & 0,507 \\
\hline VAS Walking & $7.10 \pm 2.15$ & $6.75 \pm 2.03$ & 0,360 \\
\hline Timed up and go test (sec) & $12.52=3.00$ & $12.53 \approx 2.20$ & 0.990 \\
\hline WoMAC questionnaire scores & $42.98 \approx 18.32$ & $39.85=15.59$ & 0,370 \\
\hline Synovial Fluid Amount (Right Knee) & $0.39=0.18$ & $0.32=0.15$ & 0.081 \\
\hline Synovial Fluid Amount (Left Knet) & $0.35 \neq 0.16$ & $0.39=0.19$ & 0.422 \\
\hline $\begin{array}{l}\text { Femoral Cartilage Thickness (cm) } \\
\text { (Right Knee) }\end{array}$ & $0.17 \pm 0,03$ & $0.17 \pm 0.02$ & 0,722 \\
\hline $\begin{array}{l}\text { Femoral Cartilage Thickness }(\mathrm{cm}) \\
\text { (Left Knee) }\end{array}$ & $0.17=0.02$ & $0.17=0.03$ & 0.730 \\
\hline
\end{tabular}

\begin{tabular}{|c|c|c|c|c|}
\hline Table-2 & & $\begin{array}{l}\text { Treatment group } \\
\text { (exercise + CS) n-39 }\end{array}$ & $\begin{array}{l}\text { Control group (exercise } \\
+ \text { Sham US) n-36 }\end{array}$ & p** \\
\hline \multirow{4}{*}{ VAS Rest } & Before treatment & $4.79 \pm 2.22$ & $4.11 \pm 1.86$ & \\
\hline & \begin{tabular}{|l|} 
Aftes trestment \\
\end{tabular} & $2.49 \pm 1.87$ & $2.89=2.21$ & \\
\hline & 3 months later & $2.41 \pm 2.61$ & $2.44=2.14$ & \\
\hline & $\mathrm{P}^{*}$ & $P *<0,001$ & $P *<0,001$ & 0.140 \\
\hline \multirow{4}{*}{ VAS Wallding } & Before treatment & $7.26 \pm 2.17$ & $6.75=2.04$ & \\
\hline & \begin{tabular}{|l|} 
After trestment \\
\end{tabular} & $4.08 * 2.45$ & $4.39=2.49$ & \\
\hline & 3 months later & $3.62 \pm 2.99$ & $4.31=2.44$ & \\
\hline & $\mathrm{P}^{*}$ & $P *<0,001$ & $P^{*}<0,001$ & 0.144 \\
\hline \multirow{4}{*}{$\begin{array}{l}\text { WONAC } \\
\text { questionnaire } \\
\text { scores }\end{array}$} & Before treatment & $43.84 \times 19.01$ & $41.05 \pm 13.73$ & \\
\hline & \begin{tabular}{|l|} 
After treatment \\
\end{tabular} & $27.61 \pm 18.81$ & $29.61 \pm 1598$ & \\
\hline & 3 monthi later & $25.96 \pm 18.72$ & $28.67 \pm 13.42$ & \\
\hline & P* & $P * \infty 0,001$ & $\mathbf{P}+<0,001$ & 0.281 \\
\hline \multirow{4}{*}{$\begin{array}{l}\text { Timed up and go } \\
\text { test (sec) }\end{array}$} & Before treatment & $12.85=3.10$ & $12.56 \pm 2.25$ & \\
\hline & After treatment & $11.4=1.92$ & $11.97 \pm 2.10$ & \\
\hline & 3 montha later & $11.60=2+9$ & $12.08 \pm 2.57$ & \\
\hline & P* & $P \cdot \infty 0,001$ & $P \cdot<0,001$ & 0.168 \\
\hline \multirow{4}{*}{$\begin{array}{c}\text { Synovial Fluid } \\
\text { Amount (Rizht } \\
\text { Knee) }\end{array}$} & Before treatment & $0.39 \times 0.19$ & $0.32 * 0.15$ & \\
\hline & \begin{tabular}{|l|} 
Atter trestment \\
\end{tabular} & $0.37 \pm 0.16$ & $0.34 \pm 0.15$ & \\
\hline & 3 moaths laser & $0.35=0.17$ & $0.32=0.16$ & \\
\hline & P* & $p=0.648$ & $p \cdot=0.670$ & 0.370 \\
\hline \multirow{4}{*}{$\begin{array}{c}\text { Synovial Fluid } \\
\text { Amount (Left } \\
\text { Knee) }\end{array}$} & Before treatment & $0.36 * 0.16$ & $0.37 * 0.18$ & \\
\hline & Atter treatment & $0.37 \pm 0.14$ & $0.39 \pm 0.13$ & \\
\hline & 3 months later & $0.35=0.14$ & $0.35=0.14$ & \\
\hline & P* & $P=0.263$ & $P=0.864$ & 0.888 \\
\hline \multirow{4}{*}{$\begin{array}{c}\text { Femoral Cartilage } \\
\text { Thickness (cm) } \\
\text { (Right Knee) }\end{array}$} & Before trestment & $0.17 \pm 0.03$ & $0.17 \pm 0.02$ & \\
\hline & After treatment & $0.17 \div 0.02$ & $0.17 \pm 0.02$ & \\
\hline & 3 months later & 0.1720 .03 & $0.17 \div 0.03$ & \\
\hline & p* & $p \cdot=0.86 s$ & $p=0.879$ & 0.864 \\
\hline \multirow{4}{*}{$\begin{array}{c}\text { Femoral Cartilage } \\
\text { Thickness (cm) } \\
\text { (Left Knee) }\end{array}$} & Before treatment & $0.17 \pm 0.02$ & $0.16 \pm 0.02$ & \\
\hline & \begin{tabular}{|c|} 
After treatment \\
\end{tabular} & $0.17 \pm 0.02$ & $0.16 \pm 0.02$ & \\
\hline & 3 months later & $0.17 \times 0.02$ & $0.16 * 0.02$ & \\
\hline & p. & $p \cdot=0.486$ & $p=0.59$ & 0.611 \\
\hline
\end{tabular}

Conclusion: Therapeutic ultrasound treatment in addition to home exercise program has not been shown to be effective rest and walking pain, functionality, synovial fluid and femoral cartilage thickness in the treatment of knee osteoarthritis. This is the first study to evaluate the effect of therapeutic intermittent ultrasound on synovial fluid and cartilage thickness by 
ultrasonography. International collaborative studies and randomized clinical trials will help in clarifying these areas of uncertainty.

\section{REFERENCES:}

[1] -Loyola-Sánchez, A. 2012." Effect of low-intensity pulsed ultrasound on the cartilage repair in people with mild to moderate knee osteoarthritis: a double blinded, randomized, placebo-controlled pilot study", Archives of Physical Medicine and Rehabilitation, 93(1), 35-42

Disclosure of Interests: None declared DOI: 10.1136/annrheumdis-2019-eular.6322

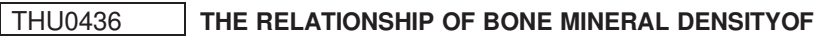 THE AXIAL SKELETON ON THE RISK OF PROGRESSION OF OSTEOARTHRITIS OF THE KNEE}

Natalia Kashevarova, Elena Taskina, Ludmila Alekseeva, Nikolay Demin, Aleksandr Lila. VA Nasonova Research Institute of Rheumatology, Moscow, Russian Federation Objectives: To find the relationship between bone minera density (BMD) and risk of knee OA progression in a 5-year prospective study. Methods: 110 females with knee OA were examined twice with 5-year interval. Examination included filling questionnaires, VAS pain assessment, plain knee radiography and axial skeleton densitometry. I stage knee OA was established in $33(30 \%)$ patients, II stage - in 46 (41,8\%, III stage - in $26(23,6 \%)$, and IV - in 5 $(4,5 \%)$. Normal lumbar vertebrae densitometry BMD values were found in 45 patients $(40,9 \%)$, osteopenia-corresponding BMD values - in $33(30,0 \%)$, and osteoporosis - in $32(29,1 \%)$. Normal femoral neck BMD values were identified in $60(54,5 \%)$ patients, osteopenia-level BMD - in 48 (43,7\%), osteoporosis - in 2 $(1,8 \%)$. In all premenopausal patients $(n=15)$ axial skeleton BMD values were normal.

Results: In 5-year interval radiographic progression was established in 40 patients (Group 2), while in 70 (Group 1) patients no progression occurred. Both groups were comparable in terms of age and disease duration, although, more patients from Group 2 tended to have normal baseline densitometry BMD values - both in lumbar vertebrae and femoral neck: $47,5 \%$ vs $37,1 \%$, and $62,5 \%$ vs $44,3 \%$ as compared to Group 1 patients. Patients from Group 1 more often had BMD values corresponding to osteoporosis and osteopenia: 32,9 vs $22,5 \%$, and 55,7 vs $37,5 \%$, respectively, as compared to Group 2 patients, although not achieving statistical significance. These differences were still identifiable after 5-year interval. Absolute BMD values at the second examination in 5 years were indicative of statistically significant increase in femoral neck and total hip BMD in Group 2 patients with knee OA progression: 0,79 \pm 0,11 vs $0,73 \pm 0,16, p<0,01$, and $0,93 \pm 0,14$ vs $0,84 \pm 0,25, p<0,05$ respectively.

Abstract THU0436 -Table 1.

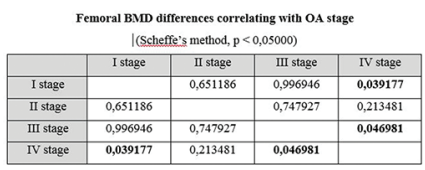

Abstract THU0436 -Table 2.

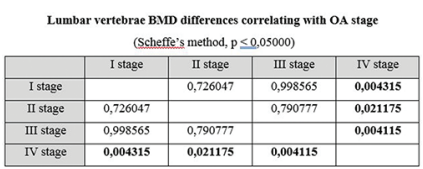

Thorough analysis of lumbar vertebrae BMD $\left(\mathrm{g} / \mathrm{cm}^{2}\right)$ relationship with $\mathrm{OA}$ stages revealed that in patients with stage IV OA lumbar BMD values were significantly higher than in patients with stages I-III OA (stage I OA

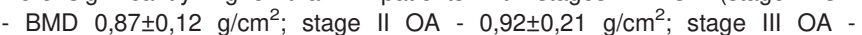

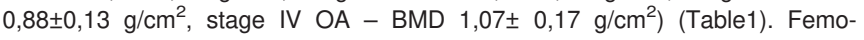
ral BMD values didn't show evident correlation with knee OA stage, although there was a trend towards higher BMD values in patients with stage IV OA compared to stage III OA $(p=0,06)$. Total hip BMD values were quite similar to lumbar BMD values $(p=0,01)$ (Table 2). BMD values were statistically significantly higher in patients with stage IV OA, than in patients with stages I and III (respectively, IV $-0,98 \pm 0,13 \mathrm{~g}$ / $\mathrm{cm}^{2}$, I $-0,85 \pm 0,10 \mathrm{~g} / \mathrm{cm}^{2}$ and III $\left.-0,86 \pm 0,16 \mathrm{~g} / \mathrm{cm}^{2}\right)$. Correlation analysis also confirmed direct correlation between knee OA stage and BMD values in all evaluated compartments $(p<0,05)$.

Conclusion: Increasing during the 5-eyar follow up period femoral neck and total hip BMD values can be interpreted as the predictor of knee PA progression. More advanced $O A$ stages are associated with higher BMD values. Future multicenter prospective studies are deemed to better establish the correlation between BMD and knee OA progression.

Disclosure of Interests:

Natalia Kashevarova: None declared, Elena Taskina Speakers bureau: Bayer, Sandoz, Boeringer-ingelheim, Ludmila Alekseeva Speakers bureau: Bayer, Boeringer-ingelheim, Gedeon-Richter, Servier, Nikolay Demin: None declared, Aleksandr Lila Speakers bureau: Sandoz, Pfizer, Abbvie, Novartis, Bayer

DOI: 10.1136/annrheumdis-2019-eular.4014

\section{THU0437 INCIDENCE OF OSTEOPOROTIC FRACTURE IN PATIENTS WITH KNEE OSTEOARTHRITIS: CLINICAL IMPACT OF FRAX-BASED OSTEOPOROSIS TREATMENT}

Bo Young Kim, Sung-Soo Kim. Gangneung Asan Hospital, Division of Rheumatology, Gangneung-si, Gangwon-do, Korea, Rep. of (South Korea)

Background: The relationship between osteoporosis and osteoarthritis is complex and controversial. Several previous studies have indicated inverse relationship between osteoporosis and osteoarthritis [1-2]. However, the increased bone mineral density in osteoarthritis does not confer a reduce risk for fractures in other studies [3-4]. From the Rotterdam study, although patients with knee osteoarthritis had a higher bone min eral density, their incident fracture risk was increased as compared with those without knee osteoarthritis [5]. Therefore, fracture risk assessment in patients with knee osteoarthritis should not be overlooked.

Objectives: We aimed to evaluate the incidence of high risk group of osteoporotic fracture in patients with knee osteoarthritis comparing the FRAX and WHO criteria. We also examined whether patients with knee $\mathrm{OA}$ differ from age, sex, and BMI matched community-based control group without knee $\mathrm{OA}$ in terms of the incidence of high risk group of osteoporotic fracture.

Methods: We retrospectively assessed 282 Korean patients with knee OA who visited 5 medical centers between November 2012 and November 2015. For control group, 991 subjects aged of $\geq 50$ years-old were enrolled in database of health chekup centers. After matching for age, sex and body mass index, 552 subjects (276 subjects in knee OA group and 276 subjects in control group) included for this study.

Results: Osteoporosis according to WHO criteria was detected 110 $(39.86 \%)$ subjects in OA group, and 101 (36.59\%) subjects in control group; these difference were not significant. However, mean FRAX major osteoporotic fracture probabilities calculated with femur neck T-score were significant different between $\mathrm{OA}$ group and control group $(7.72 \%$ vs $6.10 \%, p<0.001)$. Mean FRAX major osteoporotic fracture probabilities calculated without femur neck T-score were also significant different between OA group and control group $(8.85 \%$ vs $6.86 \%, p<0.001)$. Mean FRAX hip fracture probabilities calculated with femur neck T-score were significant different between $\mathrm{OA}$ group and control group $(2.48 \%$ vs $1.73 \%$, $p<0.001)$. Mean FRAX hip fracture probabilities calculated without femur neck T-score were also different significant between $\mathrm{OA}$ group and control group $(3.50 \%$ vs $2.37 \%, p<0.001)$. When FRAX calculations without the use of femur neck BMD was adjusted for knee OA group rather than control group, 5.9\% more patients would be recommend for osteoporosis treatment. Among the clinical risk factors of FRAX, previous fracture was significant different between knee $O A$ group and control group $(15.9 \%$ vs $0 \%, p<0.001)$. 